\title{
A responsabilidade do Estado na perspectiva da legislação da Defesa Civil e de lideranças comunitárias
}

\author{
The responsibility of the State from the perspective \\ of Civil Defense legislation and community leaders
}

La responsabilidade del Estado en vista de la legislación de la Defensa Civil y de los liderazgos comunitarios

\author{
Mary Jane Paris Spink* \\ Henrique Mota Manesco**
}

\section{Resumo}

Esta pesquisa buscou compreender a responsabilidade do Estado na gestão de risco de desastres sob a perspectiva de lideranças comunitárias do M’Boi Mirim. Tendo em vista que a região conta com 50 das 407 áreas de risco do município de São Paulo, estando entre os piores índices de exclusão e vulnerabilidade da cidade, e que compete às prefeituras gerenciar áreas de risco, verifica-se a importância de compreender a responsabilidade do Estado neste contexto. Foram analisadas entrevistas de três lideranças comunitárias da região. Desta análise emergiram diversos elementos que contribuem para a situação da região: a inércia do poder público, as dificuldades de diálogo entre população e autoridades governamentais e a diversidade de atores que interferem na solução das questões encontradas, como secretarias municipais que não conversam entre si, políticos que atuam de acordo com seus próprios interesses e a onipresença do tráfico. Verificou-se, ainda, que as lideranças tinham uma perspectiva crítica tanto com relação às ações ou inércia do governo como também com relação à responsabilidade da população.

* Graduação em Psicologia pela Universidade de São Paulo. Doutorado em Psicologia Social University of London. Estágio Pós-doutoral em Ciências Humanas na University of Cambridge, Inglaterra. Professora Titular da Pontifícia Universidade Católica de São Paulo (PUCSP) no Programa de Estudos Pós-graduados em Psicologia Social da PUCSP. Coordenadora do Núcleo de Pesquisa em Práticas Discursivas e Produção de Sentidos. Bolsista de Produtividade do CNPq. E-mail: mjspink@pucsp.br

** Bacharelado em Psicologia pela PUC-SP. E-mail: riquemanesco@hotmail.com 
Palavras-chave: Áreas de risco; desastres ambientais; Defesa Civil; responsabilidade estatal.

\section{Abstract}

The aim of this research was to understand the State's responsibility in the disaster risk management in the M'Boi Mirim regions from the perspective of the community leaders. The relevance of the focus on governmental responsibility stems from three issues: that 50 of the 407 areas of risk in the São Paulo municipality are located in this region; that it has one of the worst indicators of vulnerability in the city and that it is a duty of the municipal government to manage areas of risk. Interviews were carried out with three community leaders. Results indicate that various factors contribute to the disaster risk in the region: governmental inertia; the difficult dialogue between population and government authorities and the diversity of actors that interfere in the solution of the problem, such as lack of communication between municipal departments, politicians that act on behalf of their own interests and the omnipresence of drug trafficking. Results also indicate that community leaders have a critical view regarding governmental actions as well as the responsibility of the population.

Keywords: areas of risk; environmental disasters; Civil defense; Responsibility of the state.

\section{Resumen}

Esta investigación buscó comprender la responsabilidad del Estado en la gestión del riesgo de desastres desde la perspectiva de líderes comunitarios del barrio M’Boi Mirim. La región cuenta con 50 de las 407 zonas de riesgo del municipio de San Pablo, tiene uno de los peores índices de exclusión y vulnerabilidad de la ciudad, y dado que compete a las alcaldías gestionar estas áreas de riesgo, se ve la importancia de comprender la responsabilidad del estado en este contexto. Se analizaron las entrevistas de tres líderes comunitarios de la región. De este análisis surgieron diversos elementos que contribuyeron para la situación de la región: la inercia del poder público, las dificultades de diálogo entre la población y las autoridades gubernamentales, y la diversidad de agentes que interfieren en la solución de las cuestiones encontradas, por ejemplo, secretarias municipales que no se comunican entre sí, políticos que actúan de acuerdo a sus propios intereses y la omnipresencia del tráfico. De la misma manera, se observó que los lideres tienen una perspectiva critica con relación a las acciones o inercia, así como también con relación a la responsabilidad de la población.

Palabras claves: zonas de riesgo; desastres ambientales; Defensa Civil; responsabilidad del Estado. 
Esta pesquisa tem por foco questões associadas à gestão dos riscos relacionados a moradias em áreas vulneráveis a deslizamentos e alagamentos. Segundo Diniz Neto e Belo (2015), a temática da gestão de riscos e desastres no Brasil se aproxima da Psicologia na década de 90, em evento promovido pela Universidade Federal do Rio de Janeiro, em parceria com a Universidade Católica de Goiânia, no atendimento psicológico às pessoas atingidas pelo acidente causado pelo vazamento de Césio 137, ocorrido em Goiânia, em 1987. Em 2006, ocorre o $1^{\circ}$ Seminário Nacional de Psicologia das Emergências e dos Desastres, que reuniu representantes da defesa civil e especialistas nacionais e internacionais e, em 2011, é criado pelo Conselho Regional de Psicologia de São Paulo o Grupo de Trabalho de Emergências e Desastre (GTED), que evoluiu para o atual Núcleo sobre Psicologia em Emergências e Desastres.

Desde então, foram realizados diversos seminários acerca do tema, sobre o qual também cresceu o número de publicações, com destaque para a produção do Núcleo de Estudos e Pesquisas sobre Práticas Discursivas no Cotidiano da PUC-SP (NUPRAD). Como exemplos, podemos citar Tavanti (2013), que teve como objetivo compreender como adolescentes do bairro do Jaçanã, região Norte da cidade de São Paulo, conviviam com os riscos de desastres relacionados às chuvas; Martins (2013), que discorreu sobre o uso de tecnologias de comunicação de riscos para prevenir desastres; e Silva (2016), que abordou as múltiplas dimensões do risco para pessoas que convivem com inundações recorrentes, tendo como base um caso no $\mathrm{ABC}$ paulista.

O presente trabalho foi desenvolvido em processo de Iniciação Científica, com o apoio do CNPq, e é recorte de uma pesquisa mais ampla intitulada "Viver em Áreas de Risco", desenvolvida pelo NUPRAD, também com o apoio do CNPq, nos distritos do Jardim Ângela e Jardim São Luiz, zona sul da cidade de São Paulo (Spink, 2018). A cidade possui 407 áreas de risco, de acordo com dados fornecidos pelo site da Prefeitura de São Paulo, originados do mapeamento de áreas de risco realizado pelo Instituto de Pesquisas Tecnológicas (Brasil, 2010). Destas áreas, 50 estão localizadas na Prefeitura Regional de M’Boi Mirim, composta pelo Jardim Ângela e Jardim São Luiz, onde atualmente vivem cerca de 560 mil pessoas. Esta 
região foi se configurando ao longo dos anos em meio à contraposição entre o processo de expansão urbana e a preservação ambiental, gerando problemas, como o loteamento irregular de terras dentro de áreas protegidas. Além disso, a falta de políticas de habitação para a população de baixa renda no município propiciou o deslocamento de grandes contingentes de população para essas áreas. Conforme se verifica na Lei n. 12.608, de 10 de abril de 2012 (2012), compete às prefeituras gerenciar áreas de risco de desastres, porém a população continua vivendo em situação de risco e grande vulnerabilidade. Diante deste contexto, cabe perguntar qual tem sido o papel do Estado nesta situação.

Com base na literatura, podemos definir risco como "a possibilidade de que ações humanas e eventos naturais produzam consequências que gerem danos a coisas que são valorizadas pelos seres humanos" (Spink, 2018, p. 51). O NUPRAD tem uma linha de pesquisa sobre a 'linguagem dos riscos' na sociedade contemporânea, isto é, as diversas formas de falar sobre risco, que se desenvolvem de maneira específica dentro de territórios linguísticos definidos a partir de diferentes tradições de discursos sobre risco. Podemos apontar, por exemplo, o risco na fala de senso comum sobre perigo, concernente a experiências de infortúnios muitas vezes imprevisíveis; ou risco na perspectiva do controle e da disciplina, como forma de governamentabilidade; ou ainda o risco na perspectiva da aventura, onde a relevância está na satisfação subjetiva perante potenciais consequências (Spink, 2018).

Cada um desses territórios linguísticos desenvolve vocabulários específicos que constituem 'repertórios linguísticos', ou seja, os termos, as descrições, os lugares comuns e as figuras de linguagem que demarcam o rol de possibilidades da produção de sentidos e, como tal, circulam em diferentes modalidades de práticas discursivas, cada qual, como propõe Bakhtin (2003), com seu gênero de linguagem; alguns são mais formais, como no caso de documentos legislativos, outros menos presos a gêneros específicos, como as conversas do cotidiano.

É com base nesse referencial teórico que, nesse artigo, por meio da análise de práticas discursivas, a noção de responsabilidade do Estado é trabalhada como repertório linguístico para dar sentido à vida cotidiana. 
Considerando a problemática da gestão de riscos de desastres ambientais, a legislação sobre a Defesa Civil e tendo como base a abordagem da psicologia discursiva, o foco da pesquisa foi a visão das lideranças comunitárias da região do M’Boi Mirim sobre responsabilidade do Estado.

\section{Sobre a Defesa Civil}

O marco legal atualmente vigente no Brasil sobre a gestão de risco de desastres é a Lei n. 12.608 de 10 de abril de 2012 (2012). Esta versa sobre a Política Nacional de Proteção e Defesa Civil (PNPDEC), que engloba as ações de prevenção, mitigação, preparação, resposta e recuperação voltadas à proteção e defesa civil. É previsto que ela seja integrada a outras políticas, como ordenamento territorial, saúde, meio ambiente, educação, entre outras, a fim de se promover um desenvolvimento sustentável.

De um modo geral, o objetivo da PNPDEC é dar atenção integral à população brasileira com relação aos riscos de desastres, da prevenção à recuperação frente a eles. No que diz respeito às suas diretrizes, a PNPDEC prevê o trabalho articulado entre União, Estados, Distrito Federal e Municípios; uma abordagem sistêmica de suas ações; a prioridade de ações preventivas; a adoção da bacia hidrográfica como unidade de análise das ações de prevenção de desastres relacionados a corpos d'água; o planejamento com base em pesquisas e estudos sobre áreas de risco e incidência de desastres; e a participação da sociedade civil.

O Sistema Nacional de Proteção e Defesa Civil (SINPDEC) é constituído tanto pelos órgãos públicos - a nível federal, estadual e municipal - como também por entidades públicas e privadas de atuação significativa na área de proteção e defesa civil. Ao SINPDEC cabe o planejamento, articulação, coordenação e execução dos programas, projetos e ações com base nas diretrizes e nos objetivos da PNPDEC. A gestão do SINPDEC se dá por meio de um órgão consultivo, o Conselho Nacional de Proteção e Defesa Civil (CONPDEC); um órgão central de coordenação, que no caso é a Secretaria Nacional de Proteção e Defesa Civil (SEDEC); órgãos regionais, estaduais e municipais e órgãos setoriais dos três âmbitos do governo. [SUPRIMIDO] 
$\mathrm{Na}$ análise da Seção II da Lei n. 12.608 (2012), que versa sobre as competências dos entes federados no que diz respeito à gestão do risco de desastres, verifica-se que cabe exclusivamente à União definir as normas gerais para implementação e execução da PNPDEC e manter o Sistema Integrado de Informações sobre Desastres como forma de facilitar a gestão compartilhada.

Aos Estados cabe, exclusivamente, executar a PNPDEC em seu âmbito territorial e instituir o Plano Estadual de Proteção e Defesa Civil contendo, minimamente, a identificação das bacias hidrográficas com risco de ocorrência de desastres e as diretrizes de ação governamental no âmbito estadual, em especial no que se refere à implantação da rede de monitoramento meteorológico, hidrológico e geológico das bacias com risco de desastres.

Já aos Municípios cabe, exclusivamente, a execução da PNPDEC em âmbito local. Ou seja: a fiscalização das áreas de risco e edificações vulneráveis, procurando deslocar a população, quando for o caso, além de vedar novas ocupações nessas áreas. Cabe também mobilizar e capacitar radioamadores para atuação na ocorrência de desastre e realizar regularmente exercícios simulados, conforme Plano de Contingência de Proteção e Defesa Civil. Tudo isso como ação preventiva.

Já no que diz respeito às ações de mitigação e recuperação, compete ao município organizar e administrar abrigos provisórios para assistência à população em situação de desastre; promover a coleta, a distribuição e o controle de suprimentos em situações de desastre; proceder à avaliação de danos e prejuízos das áreas atingidas; estimular a participação de entidades privadas, associações de voluntários, clubes de serviços, organizações não governamentais e associações de classe e comunitárias nas ações do SINPDEC; promover o treinamento de associações de voluntários para atuação conjunta com as comunidades apoiadas, além de prover solução de moradia temporária às famílias atingidas.

Para além das ações exclusivas, certas ações estratégicas ocorrem em parceria entre as três instâncias governamentais. Em se tratando das ações de resposta e recuperação frente aos desastres, o Município ou Estado 
pode solicitar ajuda federal se necessitar, que pode se dar por meio da transferência de recursos financeiros, quando em situação de emergência ou calamidade pública (Instrução Normativa n.1, 2012).

No que diz respeito às ações preventivas, cabe ao Município identificar e mapear as chamadas áreas de risco, com o apoio do Estado e da União. O monitoramento meteorológico, hidrológico e geológico destas áreas também acontece com o apoio estadual e federal. Uma vez que desastres, em sua grande maioria, ocorrem em âmbito local, as áreas de risco se tornam a principal estratégia ao enfrentamento a desastres ambientais no Brasil.

Segundo Cabral (2008), podemos definir uma área de risco como "área passível de ser atingida por fenômenos ou processos naturais e/ou induzidos que causem efeito adverso [sendo que] as pessoas que habitam essas áreas estão sujeitas a danos à integridade física, perdas materiais e patrimoniais" (p. 125). Se a partir das informações técnicas sobre os terrenos e do uso e ocupação do solo de uma região, se identifica a possibilidade de ocorrência de um evento geológico, o qual pode gerar consequências sociais e/ou econômicas, pode-se considerar que esta é uma área de risco.

\section{A responsabilidade do Estado na gestão de riscos de desastres}

Quando falamos de responsabilidade estatal, estamos nos referindo a uma relação jurídica entre Estado e cidadãos. Podemos defini-la como o dever jurídico do Estado de reparar um dano decorrente de um evento lesivo da Administração Pública para com o administrado, considerando a correspondência legal (Lopes, 2011).

A noção de responsabilidade do Estado brasileiro se transformou ao longo do tempo de acordo com as teorias que orientaram cada regime constitucional. Os textos constitucionais de 1824 a 1937, por exemplo, se baseavam na teoria da responsabilidade subjetiva, na qual cabia apenas ao funcionário público causador do dano indenizar a vítima. Para que isso 
ocorresse, era necessário comprovar a culpa ou dolo por parte do agente público para que o cidadão tivesse direito à reparação do prejuízo sofrido (Moraes Filho, 2008).

De acordo com Rodrigues (2011), a responsabilização subjetiva do Estado vinha se mostrando ineficiente para a garantia de direitos dos cidadãos, uma vez que havia grande dificuldade para um simples cidadão produzir provas frente ao grande aparelhamento estatal que protegia a administração pública e seus agentes. Assim, a partir da Constituição de 1946, surgiu a teoria da responsabilidade objetiva, na qual não era mais necessária a comprovação da culpa, bastava haver o ato, o dano e o nexo causal entre eles para que se configurasse a responsabilidade (Rodrigues, 2011). Esta teoria é a que perdura até hoje, sendo expressa tanto pela Constituição Federal de (1988) quanto pelo Código Civil (Lei n. 10.406, 2002).

Neste entendimento, o Estado deve indenizar o cidadão sempre que a atividade administrativa, seja ela positiva ou decorrente de negligência, causar danos a ele. Entretanto, quando se trata de responsabilidade estatal sobre desastres, a administração pública pode vir a ser eximida da responsabilidade e o cidadão pode perder o direito de acioná-la juridicamente. Isto acontece quando a causa dos danos é caracterizada dentro das chamadas causas excludentes da responsabilidade do Estado, sendo elas a força maior e o caso fortuito. A força maior corresponde aos eventos da natureza que, caracterizados essencialmente pela sua inevitabilidade, dificultam o estabelecimento do nexo causal, segundo a teoria da responsabilidade objetiva, o que leva o poder público a eximir-se.

No cenário atual, a caracterização do desastre ambiental como sendo causa de força maior compactua com uma abordagem, tanto por parte do poder público quanto dos meios midiáticos, que privilegia as chamadas soluções técnicas, carregadas de discurso científico, voltadas ao monitoramento dos eventos naturais (chuvas, ventos, etc.). A própria permanência do adjetivo "natural” nas publicações do Ministério da Integração Nacional (Brasil, 2013, 2014), responsável pelo Sistema de Proteção e Defesa Civil, para se referir ao fenômeno dos desastres, traz a ideia de algo impossível de ser evitado, uma vez que as forças da natureza são incontroláveis. 
Este ponto de vista, entretanto, parece não levar em consideração a definição de desastre publicada pelo próprio Ministério da Integração Nacional (Brasil, 2013), que caracteriza o fenômeno como resultado de eventos adversos, sejam naturais ou provocados pelas pessoas, mas que atuam sobre um cenário vulnerável, sendo este último termo essencial para se compreender a problemática dos desastres de um ponto de vista social.

Segundo Valencio (2013), vivemos "num modelo de desenvolvimento que concentra o poder político e não afronta as desigualdades socioespaciais" (p. 27). O poder público acaba se eximindo de sua responsabilidade, restando à população atingida permanecer à própria sorte. Segundo dados dos Anuários de Desastres Naturais (Brasil 2012, 2013, 2014), em média 16 milhões de pessoas têm sido afetadas por desastres nos últimos anos no Brasil. Diante do cenário que se apresenta, reitera-se a importância de compreender e discutir responsabilidade do Estado neste contexto.

\section{Objetivo e procedimentos}

O objetivo da pesquisa foi compreender a responsabilidade do Estado na gestão de risco de desastres na visão de lideranças comunitárias da região de M’Boi Mirim, tendo como contraponto o que está previsto na atual legislação da Defesa Civil. Foram analisadas três entrevistas realizadas como parte do trabalho de campo da pesquisa "Viver em Áreas de Risco" (Spink, 2018).

As entrevistas foram feitas entre setembro de 2014 e fevereiro de 2015, seguindo um roteiro semiestruturado, tendo cada uma como disparador a experiência de um contexto no qual a entrevistada atuou como liderança comunitária, sendo estes a ocupação em margens de córregos, no caso do Córrego dos Brancos; as casas em área de risco, na Favela Erundina; e a ocupação das áreas de mananciais, no Jardim Capela. As entrevistas tiveram a duração média de $1 \mathrm{~h}$, foram gravadas e posteriormente transcritas na íntegra.

O projeto havia sido aprovado no Comitê de Ética em Pesquisa e, segundo os procedimentos éticos, todas assinaram o Termo de 
Consentimento Livre e Esclarecido, onde constava, inclusive, o respeito ao anonimato, motivo pelo qual aqui utilizamos nomes fictícios para nos referimos às entrevistadas.

A análise das entrevistas teve por base a abordagem de práticas discursivas em uma perspectiva pautada no construcionismo social. As práticas discursivas são momentos nos quais a linguagem se torna ação, quando há ressignificações, produção de sentido e posicionamento nas relações cotidianas. Sua dinâmica se dá por meio dos enunciados, elementos endereçados de uma pessoa a outra e vice-versa, e das vozes, interlocutores presentes ou presentificados nos diálogos. Essas interlocuções se dão no contexto dos gêneros de discurso, formas relativamente estáveis de comunicação que são típicos de distintos segmentos da população.

As práticas discursivas têm como elementos constituintes os repertórios linguísticos, "o conjunto de termos, descrições, lugares-comuns e figuras de linguagem que demarcam o rol de possibilidades de construções discursivas" (Spink, 2013, p. 28). A partir dos repertórios interpretativos, podemos analisar a dimensão histórica da linguagem por meio do tempo longo, do tempo vivido e do tempo curto. O tempo longo compreende os conteúdos culturais que formam os discursos de uma determinada época. O tempo vivido corresponde às experiências da história pessoal que ressignificam os conteúdos do tempo longo. E o tempo curto compreende o momento da interação face a face, por meio do qual é possível verificar como se dá a produção de sentido no processo dialógico.

As práticas discursivas, nesta abordagem, são analisadas a partir da construção de mapas dialógicos, ferramentas que permitem uma análise da dialogia presente nos discursos analisados. Dois passos iniciais embasam a elaboração do mapa: o primeiro visa a definição dos temas que integrarão os mapas. Vale apontar que uma entrevista pode abordar temas que fogem dos objetivos da pesquisa, daí a necessidade de identificar todos os temas para, no segundo passo, selecionar os trechos referentes ao tema foco da pesquisa.

Primeiramente, é realizada a leitura das transcrições das entrevistas na íntegra e a escuta do áudio para uma compreensão inicial do material e identificação dos temas presentes nos diálogos. Em seguida, são construídos 
quadros temáticos. Usamos tabelas de dupla entrada: a da esquerda para os textos e a da direita para os temas. Usamos tantas linhas quantas forem necessárias para identificação dos temas.

Uma vez definidas as categorias temáticas, o segundo passo consiste na construção dos mapas dialógicos. Utiliza-se um processador, tipo Word for Windows, e digita-se toda a entrevista. Constrói-se, então, uma tabela com o mínimo possível de colunas referentes às categorias temáticas e, usando a ferramenta "cortar" e "colar", transfere-se o conteúdo para as colunas respeitando a sequência do diálogo, criando assim um efeito "escada". Tendo em vista o foco teórico nos processos de interanimação dialógica, o diálogo entre entrevistador e participantes é mantido intacto - sem fragmentar - apenas deslocando-o para as colunas previamente definidas em função dos objetivos da pesquisa (Spink, Brigagão, Nascimento, \& Cordeiro, 2014).

Dependendo dos objetivos, os mapas podem ser construídos com todos os temas identificados ou, quando os temas se desdobram em subtemas, construímos um mapa para cada subtema. Podemos construir um mapa único com uma coluna para cada um dos cinco temas ou optar por uma análise temática mais detalhada, com mapas para cada um dos subtemas que dialogam com nossos objetivos. Entretanto, em ambas as alternativas mantemos a ordem em que apareceram as falas, apenas sintetizando os conteúdos das demais temáticas que foram abordadas.

Na presente pesquisa, foi construído um mapa para cada entrevista e foram analisadas as práticas discursivas produzidas na interação entre pesquisador e lideranças comunitárias a respeito da responsabilidade do Estado na gestão de desastres.

\section{RESULTADOS E DISCUSSÃO}

\section{Entrevista 1 - Marta e a questão das moradias em áreas de preservação ambiental}

Ao longo dos anos, Marta participou de várias lutas para implantação de creches, escolas e Unidades Básicas de Saúde (UBS) na comunidade 
em que vive. Quando se mudou, há cerca de 50 anos, a região era muito carente. Por conta disso, ela se juntou a outros integrantes da comunidade para reivindicarem seus direitos ao poder público. Como resultado dessa militância, obtiveram diversas conquistas, dentre elas a Escola Estadual Amélia Kerr Nogueira, o Centro Educacional Unificado (CEU) Vila do Sol e a UBS Integral Vera Cruz. Segundo ela, a militância acerca das questões sobre o meio ambiente e os mananciais é a mais difícil de organizar, pois uma grande parte da população tem medo de que o poder público a remova de suas casas.

Os quatro principais temas que emergiram da entrevista com Marta foram: 'Loteamento', 'Invasões', 'Poder público' e 'Áreas de risco e remoções'. O tema 'Loteamento' abarca as primeiras informações dadas pela entrevistada: Marta descreve o loteamento realizado na época em que chegou à região e a partir dele começa a falar sobre as ocupações que ocorreram. Quanto ao tema 'Invasões' (expressão utilizada pela entrevistada), Marta relata que elas ocorrem há muitos anos. Ela conta que hoje em dia faz denúncias à Prefeitura e, ainda que os moradores saibam que as denúncias partem dela, não chegam a brigar com ela, pois "eles sabem que estão errados”. Explica, inclusive, que muitas vezes quem está vivendo em áreas "invadidas" (sic) não são nem as pessoas que "invadiram" (sic), mas sim alguém que, posteriormente, comprou ou alugou a casa.

A principal noção acerca da responsabilidade do Estado que aparece neste trecho da entrevista se refere à função fiscalizadora do poder público, coerente com o que é previsto na Lei n. 12.608 (2012). A entrevistada diz que antigamente essa função era colocada em prática de forma mais frequente “a Prefeitura aquela época fiscalizava até, né?” - e que, das gestões recentes, a que mais se mostrou atuante neste sentido foi Marta Suplicy:

Quando a Marta foi prefeita, eles invadiram essa parte aqui. Ela veio e tirou. Ela tirou a primeira vez, depois vieram pela segunda vez, ela tirou de novo. Aí quando ela perdeu, ela saiu e vieram de novo e invadiram e ficou" (Entrevistada Marta).

Marta e seu marido, Carlos, que a acompanhava na entrevista, demonstram indignação tanto com os ocupantes - "A senhora viu aquela 
invasão lá? Tem cabimento um negócio daquele?” - quanto com a inércia do poder público em proteger a área - “Ave Maria, cadê o poder público?” Eles relatam que, embora a Secretaria do Meio Ambiente tenha sido alertada, não viram nenhuma atuação por parte dela e acreditam que esta inércia está diretamente relacionada com a época de eleição.

O tema 'Poder público' abarca os trechos em que atores governamentais são referidos, sendo os mais frequentes a Prefeitura, a Secretaria do Meio Ambiente ou do Verde, a Subprefeitura ${ }^{1}$ e o termo "poder público" utilizado de forma genérica, abarcando vários órgãos de governo. Ainda neste tema, durante a entrevista, Marta usa muitas vezes o pronome "Eles", generalizando a conduta a que está se referindo, seja ela ação ou inércia do poder público. Como, por exemplo, no trecho a seguir em que ela comenta a falta de ação com relação às ocupações: “[...] eu, Marta, penso que eles estão fazendo isso por causa dessa época de política, eles não estão agindo. Eu penso que seja isso, eu espero que seja isso, né? Que eles estão esperando passar essa fase pra eles agir”.

Por fim, o tema 'Áreas de risco e remoções' abarca as informações tanto do posicionamento da população como também do poder público acerca das áreas de risco e dos processos de remoção. Com relação a este tema, Marta explica que as pessoas que vivem nessas áreas se recusam a discutir sobre este assunto: "Eles têm medo de perder a casa, do poder público derrubar a casa deles, então eles recuam, entendeu?”. Em seguida, explica que a maneira mais fácil de falar sobre áreas de risco na comunidade foi organizar oficinas com a população para que eles pudessem se aproximar deste assunto e dessem ideias sobre como tratar disso na região. A partir dos resultados dessas oficinas, foi convidado um arquiteto para fazer um projeto, pois a Subprefeitura alegou não contar com arquiteto para tal atividade.

Marta parece compreender que existe uma dupla responsabilidade no que diz respeito às ocupações e às áreas de risco. Ao longo de sua fala, apresenta elementos que demonstram tanto a responsabilidade da população quanto do poder público com relação a este assunto. No que se refere

1 À época das entrevistas, as atuais Prefeituras Regionais de São Paulo eram chamadas Subprefeituras. 
à população, ela compreende o receio da perda de moradia, mas manifesta desaprovação quanto à ocupação de terras na área dos mananciais, haja vista a utilização frequente do termo invasão. Contudo, ela se posiciona também como parte dessa população - "eu não posso falar que eles são errados porque eu também sou, porque eu também estou nos mananciais" - e mostra acreditar na ação coletiva para a superação dos problemas, organizando a militância na região e sendo membro ativa do Conselho Municipal do Meio Ambiente e Desenvolvimento Sustentável.

No que se refere à responsabilidade do poder público, ela afirma que a ação deste chegou a ser efetiva em certas ocasiões, principalmente quando relacionada às remoções, mas que tem sido atravessada por questões políticas. Quando se refere às atuais ações do poder público, Marta mostra insatisfação, uma vez que elas têm sido parciais e não atendem às necessidades que a população apresenta. A inércia do poder público é mencionada com frequência e, segundo Marta, ela não se limita apenas à questão das áreas de risco, mas também com relação a outras políticas públicas. Cita a ocasião em uma escola foi reivindicada pela população, mas que foi necessário entrar na Justiça para que ela fosse entregue:

Essa escola foi pedida em 2006, foi aprovada em 2011, né? E por conta da ação, 2013 eles não começaram nada e eles entraram com ação também, com representação no ministério público, o próprio promotor determinou por causa do número de crianças fora da escola, que na época quem pediu, tinha 12, hoje tem 21 (Entrevistada Marta).

\section{Entrevista 2 - Margarida e o caso das remoções na Favela Erundina}

Margarida ocupava um cargo técnico no governo local. Trabalhou como conselheira tutelar durante seis anos e foi chamada a compor a equipe da nova gestão por já conhecer o território, onde mora desde os anos 70. Começou sua militância nesta época, inicialmente lutando por habitação, mas como a região era carente de transporte, água, luz, hospital, escola, 
etc., engajou-se em outras lutas e ressalta que muitas conquistas ocorreram por conta de movimentos sociais dos quais participou. Segundo ela, estes eram muito mais intensos e unificados naquela época.

Margarida conta que atualmente acompanha várias questões da Subprefeitura, mas que tem envolvimento maior com a Educação, com relação às creches, e com a Habitação. Esta última, principalmente por ter participado do processo de desfazimento de moradias afetadas por rachaduras devido a uma movimentação de terra na Favela Erundina, em 2014, quando acompanhou o cadastro das famílias no aluguel social e sua mudança para outros locais. Segundo ela, as maiores dificuldades neste processo foram: o diálogo que o poder público precisou ter com o tráfico na região; o jogo de cintura que precisava ter para lidar com o governo e com as lideranças comunitárias; e a demora com relação à liberação do aluguel social, o que fez muitas famílias voltarem a ocupar os locais de onde haviam sido removidas.

Embora visualize muitos obstáculos, ela diz contar com um subprefeito bastante motivado, com associações de moradores que se juntam à luta pela preservação das nascentes, com a valorização da região pela chegada do metrô. Porém, se mostra bastante preocupada com o crescimento desordenado da região.

Embora faça parte da equipe de profissionais de um órgão público, Margarida reconhece diversas vezes a "ineficácia das ações do governo", situação em que ela demonstra uma postura crítica, como por exemplo, quando cita a demora na liberação do aluguel social:

E acho que foi assim uma coisa que a gente fica frustrado que a demora é muito grande. Nós temos pessoas cadastradas na habitação hoje, no aluguel social, que tem mais de vinte anos. (...) Então é muito tempo! Então eu fico assim, às vezes eu me faço essa pergunta: porque esperar tanto tempo?; e em outro momento, critica: Nossa, tem não sei quantos mil cadastros. Não vai dar conta. O Governo gasta por mês milhões e milhões de aluguel social (Entrevistada Margarida).

Outro momento em que ela demonstra essa postura crítica é quando fala sobre as ações pós-remoção de áreas ocupadas: 
Porque nós não temos essa secretaria que sai lá ou alguém que assume, que saiu, tirou a família, mas faz um parque, uma praça, qualquer coisa que tem que fazer, mas não deixa a área livre. Isso é um saco sem fundo que você nunca vai dar conta, o governo nunca vai dar conta se não investir nesse projeto (Entrevistada Margarida).

Com esses exemplos, Margarida nos permite entender a situação precária do território. Muitos moradores que foram removidos chegaram a receber o Auxílio-aluguel, uma das alternativas de atendimento habitacional, regularizado pela Portaria 323/10 (2010), da Secretaria Municipal de Habitação. Entretanto, o valor oferecido pelo poder público geralmente não é suficiente para cobrir os aluguéis dos imóveis disponíveis nas proximidades.

Além disso, a falta de monitoramento adequado da utilização desse auxílio por parte do poder público acabou contribuindo, ao contrário do que se propõe, para a permanência das situações de precariedade habitacional no município. Segundo dados do Caderno para discussão pública do Plano Municipal de Habitação, em abril de 2016, o Auxílio-aluguel contemplava 27.941 famílias e sua soma havia ultrapassado $\mathrm{R} \$ 110$ milhões utilizados em 2015. Destas famílias, verificou-se que grande parte tinha encontrado sua moradia no mercado informal, sem resolver, portanto, sua situação de precariedade, ou utilizando o recurso como complementação da renda familiar, enquanto compartilhava a moradia com parentes e amigos (Prefeitura Município de São Paulo, 2016, p. 47).

Ao longo da entrevista, Margarida expressa diversas dificuldades que a Subprefeitura enfrenta para atuar na região. Dentre os maiores obstáculos, ela cita a burocracia:

A questão da burocracia é muito ruim pra nós. Porque se você... Vamos supor: tem uma equipe próxima da Subprefeitura, do Governo, do cadastro. Você pede uma coisa, fala: 'Olha, eu quero que você levante isso no cadastro'. As pessoas têm muita má vontade. Então, demora muito por isso. Enquanto você não levanta isso, pra você saber se aquela área é particular, ou se é pública, então isso é que vai crescendo as invasões, em locais que não deve (Entrevistada Margarida). 
Margarida também faz uma crítica à corrupção existente nos fluxos mais básicos dos serviços da região, como por exemplo, em locais que estão sendo desmatados e que precisariam de uma fiscalização mais intensa. Diz ela, - “Tem pessoas que vão lá, leva propina e acaba deixando passar, vão fazendo vista grossa, vai que isso passa (...)”. Outras dificuldades expressadas por ela dizem respeito ao diálogo entre as políticas públicas, a descentralização dos serviços públicos e a falta de informação da grande maioria da população. Todas essas questões, em seu entendimento, agravam a situação de vulnerabilidade na qual as pessoas da região vivem e fazem as possibilidades de transformação dessa realidade tornarem-se mais distantes.

Por fim, o tema 'Postura da população' abarca os trechos em que Margarida descreve como a população reage às questões de seu território e também como ela contribui para a realidade local. Neste caso, ela cita diversas pessoas que retornaram às suas casas mesmo depois de serem desapropriadas, uma vez que não tinham para onde ir e pelo fato de que o aluguel social não era suficiente para conseguir pagar um aluguel nas redondezas. Segundo ela, as pessoas continuam querendo "invadir" (sic) áreas de mananciais e continuam ocupando desordenadamente o território. Tentam, ainda, receber aluguel social sem se encaixar nas condições previstas por lei e isso tudo por falta de informação, segundo seu entendimento.

\section{Entrevista 3 - Joice e as moradias à beira de córregos}

Joice mora na região há trinta e dois anos. Em 2007, começou a trabalhar como técnica em um núcleo que atendia e acompanhava adolescentes em medida socioeducativa em meio aberto. No mesmo ano, ingressou na faculdade de Pedagogia, tendo se formado pela UNIP em 2010. Sobre esse trabalho, Joice destaca a dimensão da problemática da vulnerabilidade social com a qual se depara em suas andanças e experiências pela região, relatando vários exemplos de adolescentes com quem teve contato, suas condições de vida e a compreensão do quanto seu contexto contribuía para as situações que vivenciavam. Enquanto trabalhava no núcleo com adolescentes, Joice foi convidada a compor a equipe deuma organização não governamental voltada ao desenvolvimento de área na mesma região. 
Neste programa, atuou em diversos episódios que envolveram situações de risco, como por exemplo, no alagamento do córrego da Moenda Velha, e também no alagamento do Córrego dos Brancos.

Para esta terceira entrevista foram identificados os temas: 'Ações da ONG', 'Ação do poder público', 'Inércia do poder público' e 'Papel da população'. O primeiro tema diz respeito às ações da ONG na comunidade. Como técnica da ONG, ela relata vários momentos em que atuou como mediadora de situações no território, como por exemplo, no alagamento do Córrego dos Brancos. Sobre este episódio ela conta:

Aí como eu já tinha o telefone do subprefeito, (nome suprimido) liguei pra ele: '(Nome suprimido), tá acontecendo isso, isso aqui...' Daí já liguei para o(Nome suprimido): 'Olha, tá acontecendo isso aqui, o pessoal quer subir, quer juntar o pessoal da Palestina, não vai dar certo isso aqui, é perigoso ter vítimas' (Entrevistada Joice).

O tema 'Ação do poder público' contém os trechos em que equipamentos e órgãos do governo entraram em ação, entre os quais ela cita a Defesa Civil, o Centro de Referência de Assistência Social (CRAS), entre outros, inclusive a Polícia que aparece no episódio do Córrego dos Brancos e tenta interferir na mobilização da comunidade: "aí chega a polícia, os policiais já querendo dar tiro (...) e ele continuou com a arma apontada. (...) E ele: 'O que tá tendo aqui é bagunça!' (...) e daí eles chegaram e ainda bateram em alguns meninos, dentro da comunidade”.

O tema 'Inércia do poder público' abarca os trechos em que Joice expressa a falta de ação do poder público e até mesmo a ineficácia das ações realizadas para resolver os problemas da comunidade. Sobre a falta de ação, ela relata a falta de auxílio no momento do alagamento -“que não fazia contexto daqui, mas podia orientar né. Acho que a comunicação não precisa ser a pessoa especializada, mas poderia ter orientado e não teria acontecido o que aconteceu"; a falta de acolhimento por equipamentos das políticas públicas, como a saúde: 
Porque eu acredito que a Saúde tinha que estar lá de uma maneira... eu sei que não ia fazer nada, mas de uma maneira de orientar as pessoas, o risco que elas estavam tendo, porque até quinze dias pode aparecer um sintoma, e não foi orientado (Entrevistada Joice).

E também fala sobre a falta de trabalhos de conscientização dentro da comunidade, sendo que o único que ela conhece é o que ela mesma realiza na ONG.

Por fim, o tema 'Papel da população' contém os trechos em que Joice fala sobre a maneira em que a população reage às questões que lhe acometem:

Perguntei, aí falaram que tinha alagado, que tinha subido a água, e que eles tinham tirado as coisas que se perderam na enchente e colocado na rua para chamar a atenção das autoridades. [...] Quando eu cheguei 7 horas da manhã, estava lotado de crianças, veio chegando crianças com fome, querendo café (Entrevistada Joice).

Neste tema também aparece a postura da população na questão da habitação:

Olha, ninguém quer sair daqui. Tá ruim, mas tá bom, é assim. Tem que sair o córrego e tem que fazer moradia. Eles falam: 'Joice, por que não tira esse córrego daqui?' Então, o problema de tudo não são eles que moram em cima do córrego, é o córrego que tá ali, o problema é o córrego, não são eles (Entrevistada Joice).

Assim como as outras entrevistadas, Joice demonstra uma postura crítica frente à inércia do governo com relação à questão das ocupações em áreas de mananciais, tanto no que diz respeito às ações de prevenção:

Tão fácil né, eu lembro que eu estudava na minha quarta séria bacia geográfica, planície, relevo, na,na,na... e hoje eu vejo que eu estou numa bacia geográfica. (risos) Aí eu falei: 'Que custa, (nome suprimido), a escola que tá lá, em cima da bacia, vir pra base e mostrar isso pras crianças de quarta série? Uma bacia geográfica é isto.' E eu ficava pensando que eu nunca vi. Eu saia da minha casa, subia o escadão e pegava a avenida direto, né, era mais relevo né, do que uma bacia. Aí falei, gente eu sofri tanto para entender o que é isso (Entrevistada Joice). 
Como também com relação à abordagem das pessoas atingidas na hora do evento, seja a negligência do equipamento de saúde que não apareceu para orientar as pessoas acerca da prevenção de doenças, seja a ação policial que chegou para reprimir a manifestação dos moradores que haviam perdido seus pertences.

Joice demonstra, ainda, seu desconforto pelo fato da população não se mobilizar ou se engajar, às vezes por falta de oportunidade, em muitas das lutas da comunidade:

É hilário, então a gente tem uma riqueza pra estudo, tanto acadêmico quanto ensino fundamental, ensino fundamental I e II, ensino médio, né, a gente tem essa riqueza tão grande e valiosa e a gente deixa o outro que vem lá do outro lado da ponte que não tem risco, não tem vulnerabilidade, para fazer a pesquisa numa lugar de vulnerabilidade, enquanto nós mesmos poderia estar relatando, fazendo algo para mudar isso aqui, agregando forças (Entrevistada Joice).

\section{CONSIDERAÇÕES FINAIS}

Os mapas dialógicos construídos a partir da abordagem das práticas discursivas possibilitaram dar visibilidade para os sentidos atribuídos pelas entrevistadas à responsabilidade governamental, sendo que três temas tiveram destaque. O primeiro concerne à inércia das autoridades governamentais no controle das ocupações da região. Embora legalmente responsável, o poder público parece não tomar providências frente a isso ou demorar muito para tal. Quando há ação, esta tem se mostrado ineficaz para suprir as necessidades da região. A falta de fiscalização de áreas de mananciais e áreas de risco, a demora na liberação e insuficiência do auxílio habitacional e o abandono, por parte do poder público, dos locais que antes haviam sido ocupados pela população, faz com que as ocupações continuem, gerando assim um círculo vicioso.

O segundo tema envolve as dificuldades de diálogo entre população (e seus porta-vozes, as lideranças) e as autoridades governamentais. $\mathrm{Na}$ visão das entrevistadas, o poder público aparece diversas vezes como um poder repressor, seja na forma como a polícia intervém em eventos mais críticos, seja pelo próprio poder das ações de remoção. Do ponto de vista da 
população, além de causar retraimento e medo, essa característica parece prevalecer à ideia de um Estado que tem como dever adotar medidas necessárias para a gestão dos riscos de desastre e o diálogo entre a população e o poder público fica, então, comprometido.

Cabe destacar que, em se tratando de uma política de Defesa Civil que se coloca como intersetorial, embora o foco de responsabilidade do Estado pareça se voltar com maior intensidade para a política habitacional, a ineficácia das outras políticas acaba por contribuir para o problema. Retomando a PNPDEC, de fato as ações são previstas para além das políticas habitacionais. Porém, não são encontradas muitas destas ações na região por parte do poder público. Como forma de superar estas dificuldades, há um intenso trabalho das lideranças em despertar a participação da população na redução de riscos de desastres, conforme prevê a PNPDEC.

Por fim, o terceiro tema introduz a presença de muitos atores na solução e/ou negligência dos problemas encontrados: secretarias que não conversam entre si; políticos que só defendem seus interesses e a onipresença do tráfico. A PNPDEC deve integrar-se às demais políticas públicas, mas o que se percebeu é que há bastante burocracia nos fluxos de ação. Os equipamentos e serviços que deveriam ser integrados são muito distantes uns dos outros, até por conta do desenvolvimento desordenado da região, o que dificulta o trabalho das equipes; o deslocamento da população no cotidiano e o acesso à saúde e educação são dificultados pela falta de transporte adequado. Há também, segundo as entrevistadas, má vontade dos responsáveis que trabalham nos serviços públicos, além da corrupção, o que prejudica ainda mais o desenvolvimento das ações de maneira ágil.

As três lideranças destacaram tanto a falta de responsabilidade por parte da população quanto dos agentes governamentais e acreditam que as ações de ambos tem se pautado exclusivamente por interesses individuais. Os períodos eleitorais, por exemplo, parecem interferir diretamente nas ações governamentais com vistas à manutenção do poder e da ideologia de determinados partidos, em detrimento do interesse e da urgência de questões coletivas. Como diz Margarida -"É pelo seu interesse, hoje em dia está assim pelo seu grupo, pelo seu interesse e aí a gente vai lá, o interesse do povo fica em segundo". 
Por fim, as lideranças ainda parecem responsabilizar a população com relação à situação em que vivem, ainda que também compreendam que a precariedade das condições é responsabilidade governamental. Esta dupla perspectiva aparece, inclusive, no uso do termo "invasão" e seus derivados para se referir às ocupações. Os moradores da região convivem com múltiplas formas de ocupação do território, algumas, sim, pautadas em uma postura política sobre direito à terra, mas outras ancoradas em especulação imobiliária ou no uso político de "fazer vistas grossas" às construções em áreas totalmente protegidas, o que leva à polissemia do uso. A ineficácia do poder público em proporcionar alternativas para a atual situação parece estar longe de ser resolvida e as lideranças comunitárias se mostram pessimistas quanto a isso.

\section{REFERÊNCIAS}

Bakhtin, M. (2003). Os gêneros do discurso. In P. Bezerra (Org.), Estética da criação verbal (pp.261-306). São Paulo, SP: Martins Fontes.

Brasil. (1988). Constituição da República Federativa do Brasil. Brasília, DF: Senado.

Brasil. Instituto de Pesquisas Tecnológicas. (2010). Análise e mapeamento de riscos associados a escorregamentos em áreas de encostas e a solapamentos de margens de córregos em favelas do município de São Paulo - Subprefeitura de M’Boi Mirim. Relatório no 118.650205. São Paulo: IPT.

Brasil. Ministério da Integração Nacional, Secretaria Nacional de Defesa Civil, Centro Nacional de Gerenciamento de Riscos e Desastres. (2012). Anuário brasileiro de desastres naturais 2011. Brasília, DF: Autor. Recuperado de http://www.mi.gov.br/c/ document_library/get_file?uuid=e3cab9o6-c3fb-49fa-945d649626acf79o\&groupId $=185960$ 
Brasil. Ministério da Integração Nacional, Secretaria Nacional de Defesa Civil, Centro Nacional de Gerenciamento de Riscos e Desastres. (2013). Anuário brasileiro de desastres naturais 2012. Brasília, DF: Autor. Recuperado de http://www.mi.gov.br/c/document_library/get_ file?uuid=f22ccccd-281a-4b72-84b3-654002cff1e6\&groupId=185960

Brasil. Ministério da Integração Nacional, Secretaria Nacional de Defesa Civil, Centro Nacional de Gerenciamento de Riscos e Desastres. (2014). Anuário brasileiro de desastres naturais 2013. Brasília, DF: Autor. Recuperado de http://www.mi.gov.br/c/ document_library/get_file?uuid=fee4007a-abob-403e-bb1a8aaoo38563ob\&groupId=10157

Cabral, J. (2008). Mapeamento de áreas de risco de inundações e enchentes. In Brasil - Ministério das Cidades, Curso de gestão e mapeamento de riscos socioambientais (pp. 124-129). [Versão digital em Adobe Reader]. Recuperado de www.ceped.ufsc.br/wp-content/ uploads/2014/o7/Curso_Gestao_apostila.pdf

Diniz Neto, O., \& Belo, F. R. R. (2015). Psicologia das emergências. Gerais: Revista Interinstitucional de Psicologia, 8(spe), 284-299. Recuperado de http://pepsic.bvsalud.org/scielo.php?script=sci_ arttext\&pid=S1983-82202015000200010\&lng =pt\&tln $\mathrm{g}=\mathrm{pt}$.

Instrução Normativa n.1, de 24 de agosto de 2012 (2012). Estabelece procedimentos e critérios para a decretação de situação de emergência ou estado de calamidade pública pelos Municípios, Estados e pelo Distrito Federal, e para o reconhecimento federal das situações de anormalidade decretadas pelos entes federativos e dá outras providências. [Versão digital em Adobe Reader]. Recuperado de www. defesacivil.sp.gov.br/v2010/portal.../InstrucaoNormativa24082012. pdf

Lei n. 10.406, de 10 de Janeiro de 2002 (2002). Institui o Código Civil. Recuperado de http://www.planalto.gov.br/ccivil_03/leis/2002/ L10406.htm 
Lei n. 12.608, de 10 de abril de 2012. (2012). Institui a Política Nacional de Proteção e Defesa Civil - PNPDEC; dispõe sobre o Sistema Nacional de Proteção e Defesa Civil - SINPDEC e o Conselho Nacional de Proteção e Defesa Civil - CONPDEC; autoriza a criação de sistema de informações e monitoramento de desastres. Recuperado de http:// www.planalto.gov.br/ccivil_03/_ato2011-2014/2012/lei/l126o8.htm

Lopes, H. R. (2011). A responsabilidade civil do estado e a teoria do risco integral. Revista Âmbito Jurídico, 95. Recuperado de http://www.ambito-juridico.com.br/site/?n_link=revista_ artigos_leitura\&artigo_id $=10776$

Martins, M. H. M. (2013). O uso de tecnologias de comunicação de riscos para prevenir desastres (Dissertação de Mestrado). Pontifícia Universidade Católica de São Paulo, São Paulo.

Moraes Filho, J. G. C. (2008). Responsabilidade civil do Estado: histórico das Constituições brasileiras. Revista Âmbito Jurídico, 53, (paginação irregular). Recuperado de http://www.ambito-juridico.com.br/ site/?n_link=revista_artigos_leitura\&artigo_id $=2880$

Portaria $n^{0} 323$ (2010, 13 agosto). Estabelece as alternativas de atendimento habitacional, para o Programa "Ações de Habitação", fixa os valores limites dos auxílios e regulamenta a utilização dos recursos para atendimento às famílias. Diário Oficial da Cidade de São Paulo, $\mathrm{n}^{0}$ 151, São Paulo-SP. Recuperado de: http://www.docidadesp. imprensaoficial.com.br/NavegaEdicao.aspx?ClipId=3HVNN3J4G3 VCCe421M5ET130KJ4

Prefeitura do Município de São Paulo. Secretaria Municipal de Habitação e Companhia Metropolitana de Habitação de São Paulo. (2016). Plano Municipal de Habitação de São Paulo - Caderno para discussão pública. [Versão digital em Adobe Reader]. Recuperado de http:// www.habitasampa.inf.br/files/CadernoPMH.pdf

Rodrigues, R. R. (2011). A Responsabilidade Civil do Estado. Revista Âmbito Jurídico, 94, (paginação irregular). Recuperado de http:// www.ambito-juridico.com.br/site/?n_link=revista_artigos_ leitura\&artigo_id=10745 
Silva, S. L. A. (2016). As múltiplas dimensões do risco para pessoas que convivem com inundações recorrentes: o caso de moradores da Vila América, Santo André/SP (Dissertação de Mestrado). Pontifícia Universidade Católica de São Paulo, São Paulo.

Spink, M. J. P. (Org.). (2013). Práticas discursivas e produção de sentidos no cotidiano: aproximações teóricas e metodológicas. [Versão digital em Adobe Reader]. Recuperado de http://www.bvce.org.br/ DownloadArquivo.asp?Arquivo=SPINK_Praticas_discursivas_e_ producao_FINAL_CAPA_NOVAc.pdf

Spink, M. J. P. (2018). Viver em áreas de risco: reflexões sobre vulnerabilidades socioambientais. São Paulo, SP: Terceiro Nome.

Spink, M. J. P., Brigagão, J. I. M., Nascimento, V. L. V., \& Cordeiro, M. P. (Orgs.). (2014). A produção de informação na pesquisa social: compartilhando ferramentas. [Versão digital em Adobe Reader]. Recuperado de http://www.bvce.org.br/DownloadArquivo. asp?Arquivo=SPINK_A_producao_de_informacao.pdf

Tavanti, R. M. (2013). Risco, desastre e prevenção: um estudo sobre estratégias coletivas na ótica de adolescentes moradores do bairro do Jaçanã (Dissertação de Mestrado). Pontifícia Universidade Católica de São Paulo, São Paulo.

Valencio, N. (2014). Desastre como Prática Sociopolítica de Solapamento da Segurança Humana. In R. Carmo, \& N. Valencio (Orgs.), Segurança humana no contexto dos desastres. [Versão digital em Adobe Reader]. Recuperado de http://www.fmclimaticas.org.br/ wp-content/uploads/2014/o4/SegurancaHumana_e-book.pdf 